\title{
Commentary: New Insights in Anorexia Nervosa
}

\author{
Per Södersten *, Cecilia Bergh and Michael Leon \\ Section of Applied Neuroendocrinology, Mandometer Clinic, Karolinska Institutet, Huddinge, Sweden
}

Keywords: anorexia nervosa, dopamine, ghrelin, physiology, treatment

\section{A commentary on}

New Insights in Anorexia Nervosa

by Gorwood, P., Blanchet-Collet, C., Chartrel, N., Duclos, J., Dechelotte, P., Hanachi, M., et al. (2016).

Front. Neurosci. 10:256. doi: 10.3389/fnins.2016.00256

In a comprehensive overview of the concomitants of anorexia nervosa (AN), Dr. Gorwood and collaborators list nine hormones "driving of the reward aspect of thinness" and "abnormal satiety feedback," and they incorporate new neuropeptides, sociocultural, psychological, psychiatric comorbidity, genetic, epigenetic and gut microbiological factors and 11 risk factors into a "holistic model of AN," including "body, brain and mind".

We regard this list of potential mechanisms underlying AN as introducing redundant complexity to an area of study that continually mistakes the causes of AN with the responses to starvation that are the consequences of the disorder (Södersten et al., 2008, 2014, 2016; Zandian et al., 2015). In particular, we wish to comment on two of the topics that the authors discuss: the response of the mesolimbic dopamine neurons to a reduction in the availability of food and the change in the levels of ghrelin that is associated with AN.

\section{DOPAMINE AND STARVATION}

To meet the challenge of starvation, animals have developed efficient foraging strategies that are mediated by dopamine (Stephens and Krebs, 1986; Faure et al., 2008; O'Connell and Hofmann, 2011; Richard and Berridge, 2011; McCue, 2012; Bédécarrats et al., 2013; Moe et al., 2014; Søvik et al., 2014; Masek et al., 2015). Moreover, hunger hormones influence how animals relate to environmental food cues by acting on dopamine neurons (Cone et al., 2015). For example, dopamine is involved in evaluating the hedonic aspects of food (Berridge and Kringelbach, 2015) and increases in response to the initial food restriction in patients who become anorexic, thereby encouraging the continuation of such behavior (Södersten et al., 2008). Indeed, such neural changes may have been necessary to allow some individuals in the population to withstand famine, the major challenge to humans on this planet until recent times. Therefore, changes in the responses of the mesolimbic dopamine terminals in the ventral striatum of AN patients, which Dr. Gorwood and collaborators discuss, should be understood as the normal physiological response to starvation (Södersten et al., 2016).

We proposed that increased mesolimbic dopamine activity initially supports food restriction, and as food restriction results in severe weight loss, it precipitates the other features of the disorder (Södersten et al., 2008; Ioakimidis et al., 2011). 


\section{GHRELIN AND STARVATION}

Because AN patients eat very little food, Dr. Gorwood and collaborators find the increase in the level of ghrelin, an "orexigen," in AN "paradoxical" and they suggest that anorexics have a "global resistance to orexigenic signals." However, this conclusion is inappropriate, just as the reconsideration of the "neuropeptide tyrosine (NPY) paradox" has demonstrated. Thus, whereas sedentary rats eat more food when treated with NPY, they increase their foraging for food, but eat less when food availability is restricted (Södersten et al., 2008). An "orexigenic" hormone, NPY, turns into an "anorexigen" when the food environment changes from abundance to scarcity, questioning the usefulness of the concept of orexigens and anorexigens (Zandian et al., 2015). Similarly, the older concepts of excitation and inhibition exerted by anatomically separable hypothalamic centers that were thought to maintain body weight homeostasis (Stellar, 1954) also seem not to be applicable to the normal control of food intake (Södersten et al., 2008).

In the same way, ghrelin stimulates foraging when the supply of food is continuously limited, but it stimulates eating when food is temporarily removed (Méquinion et al., 2015). Far from being "paradoxical" or even "inappropriate," increased physical activity associated with low leptin levels and high plasma concentrations of ghrelin are adaptations to a long-term reduction in food intake by encouraging the production of heat to maintain thermal homeostasis in individuals whose surface area remains the same, but whose body mass that produces heat has greatly diminished. This response is therefore beneficial, rather than pathological in experimental animals or AN (Méquinion et al., 2015). These changes in ghrelin may be a response to low body weight and low food intake, as constitutionally thin women also have high levels of ghrelin (Tolle et al., 2003). In addition, the hypothalamic neurons of mice, previously thought to be sensors of metabolic status, respond immediately to the introduction of food into their environment, even when pre-treated with ghrelin, supporting the

\section{REFERENCES}

Bédécarrats, A., Cornet, C., Simmers, J., and Nargeot, R. (2013). Implication of dopaminergic modulation in operant reward learning and the induction of compulsive-like feeding behavior in Aplysia. Learn. Mem. 20, 318-327. doi: 10.1101/lm.029140.112

Bergh, C., Brodin, U., Lindberg, G., and Södersten, P. (2002). Randomized controlled trial of a treatment for anorexia and bulimia nervosa. Proc. Natl. Acad. Sci. U.S.A. 99, 9486-9491. doi: 10.1073/pnas.142284799

Bergh, C., Callmar, M., Danemar, S., Hölcke, M., Isberg, S., Leon, M., et al. (2013). Effective treatment of eating disorders: results at multiple sites. Behav. Neurosci. 127, 878-889. doi: 10.1037/a0034921

Bergh, C., and Södersten, P. (1996). Anorexia nervosa, self-starvation and the reward of stress. Nat. Med. 2, 21-22. doi: 10.1038/nm0196-21

Berridge, K. C., and Kringelbach, M. L. (2015). Pleasure systems in the brain. Neuron 86, 646-664. doi: 10.1016/j.neuron.2015.02.018

Chen, Y., Lin, Y. C., Kuo, T. W., and Knight, Z. A. (2015). Sensory detection of food rapidly modulates arcuate feeding circuits. Cell 160, 829-841. doi: 10.1016/j.cell.2015.01.033

Cone, J. J., Roitman, J. D., and Roitman, M. F. (2015). Ghrelin regulates phasic dopamine and nucleus accumbens signaling evoked by food-predictive stimuli. J. Neurochem. 133, 844-856. doi: 10.1111/jnc.13080 idea that ghrelin does not actually control food intake (Chen et al., 2015).

\section{EFFECTIVE TREATMENT FOR ANOREXIA NERVOSA}

We have suggested that treatment of AN should focus on the disordered eating behavior, which is the major behavioral marker of AN, and that the other aspects of the anorexic phenotype emerge as a consequence of starvation and that they will also return to normal when eating behavior and food intake have been normalized (Bergh and Södersten, 1996). Indeed, in a randomized clinical trial, we showed that such a therapy is effective for AN (Bergh et al., 2002). Moreover, the outcome of this treatment for 1428 patients, including all eating disorders diagnoses, had a remission rate of $75 \%$, with a rate of relapse of $10 \%$ over 5 years of follow-up, and no patient has died in treatment or follow-up (Bergh et al., 2013).

In stark contrast, as Dr. Gorwood and collaborators pointed out, standard treatments have very limited effect on $\mathrm{AN}$, which is therefore associated with "the highest mortality rate of all psychiatric disorders ... and exceptionally high relapse rates." We therefore think that considering the complexities of the interactions between AN and starvation, while interesting, will be unlikely to lead to an even more effective treatment for this disorder.

\section{AUTHOR CONTRIBUTIONS}

All authors contributed to this work and approved it for publication.

\section{FUNDING}

This work was supported by Mando Group AB.

Faure, A., Reynolds, S. M., Richard, J. M., and Berridge, K. C. (2008). Mesolimbic dopamine in desire and dread: enabling motivation to be generated by localized glutamate disruptions in nucleus accumbens. J. Neurosci. 28, 7184-7192. doi: 10.1523/JNEUROSCI.4961-07.2008

Ioakimidis, I., Zandian, M., Ulbl, F., Bergh, C., Leon, M., and Södersten, P. (2011). How eating affects mood. Physiol. Behav. 103, 290-294. doi: 10.1016/j.physbeh.2011.01.025

Masek, P., Worden, K., Aso, Y., Rubin, G. M., and Keene, A. C. (2015). A dopamine-modulated neural circuit regulating aversive taste memory in Drosophila. Curr. Biol. 25, 1535-1541. doi: 10.1016/j.cub.2015. 04.027

McCue, M. D. (2012). Comparative Physiology of Fasting, Starvation, and Food Limitation. Berlin; Heidelberg: Springer-Verlag.

Méquinion, M., Caron, E., Zgheib, S., Stievenard, A., Zizzari, P., Tolle, V., et al. (2015). Physical activity: benefit or weakness in metabolic adaptations in a mouse model of chronic food restriction? Am. J. Physiol. Endocrinol. Metab 308, E241-E255. doi: 10.1152/ajpendo.00340.2014

Moe, R. O., Nordgreen, J., Janczak, A. M., Bakken, M., Spruijt, B. M., and Jensen, P. (2014). Anticipatory and foraging behaviors in response to palatable food reward in chickens: effects of dopamine D2 receptor blockade and domestication. Physiol. Behav. 133, 170-177. doi: 10.1016/j.physbeh.2014.05.023 
O'Connell, L. A., and Hofmann, H. A. (2011). The vertebrate mesolimbic reward system and social behavior network: a comparative synthesis. J. Comp. Neurol. 519, 3599-3639. doi: 10.1002/cne.22735

Richard, J. M., and Berridge, K. C. (2011). Nucleus accumbens dopamine/glutamate interaction switches modes to generate desire versus dread: $\mathrm{D}(1)$ alone for appetitive eating but $\mathrm{D}(1)$ and $\mathrm{D}(2)$ together for fear. J. Neurosci. 31, 12866-12879. doi: 10.1523/JNEUROSCI.1339-1 1.2011

Södersten, P., Bergh, C., Leon, M., and Zandian, M. (2016). Dopamine and anorexia nervosa. Neurosci. Biobehav. Rev. 60, 26-30. doi: 10.1016/j.neubiorev. 2015.11.003

Södersten, P., Bergh, C., Zandian, M., and Ioakimidids, I. (2014). Homeostasis in anorexia nervosa. Front. Neurosci. 8:234. doi: 10.3389/fnins.2014. 00234

Södersten, P., Nergårdh, R., Bergh, C., Zandian, M., and Scheurink, A. (2008). Behavioral neuroendocrinology and treatment of anorexia nervosa. Front. Neuroendocrinol. 29, 445-462. doi: 10.1016/j.yfrne.2008.06.001

Søvik, E., Even, N., Radford, C. W., and Barron, A. B. (2014). Cocaine affects foraging behaviour and biogenic amine modulated behavioral reflexes in honey bees. PeerJ 2:e662. doi: 10.7717/peerj.662

Stellar, E. (1954). The physiology of motivation. Psychol. Rev. 61, 5-22. doi: $10.1037 / \mathrm{h} 0060347$
Stephens, D. W., and Krebs, J. R. (1986). Foraging Theory. Princeton: Princeton University Press.

Tolle, V., Kadem, M., Bluet-Pajot, M. T., Frere, D., Foulon, C., Bossu, C., et al. (2003). Balance in ghrelin and leptin plasma levels in anorexia nervosa patients and constitutionally thin women. J. Clin. Endocrinol. Metab. 88, 109-116. doi: 10.1210/jc.2002-020645

Zandian, M., Bergh, C., Ioakimidis, I., Esfandiari, M., Shield, J., Lightman, S., et al. (2015). Control of body weight by eating behavior in children. Front. Pediatr. 3:89. doi: 10.3389/fped.2015.00089

Conflict of Interest Statement: PS and CB own 47.5\% each and ML owns 5\% in the stock of Mando Group AB, the company that treats patients with eating disorders through contractual agreements with the City Council of Stockholm. All health care, provided by public as well as private clinics, is publically funded by such contracts in Sweden.

Copyright (c) 2016 Södersten, Bergh and Leon. This is an open-access article distributed under the terms of the Creative Commons Attribution License (CC BY). The use, distribution or reproduction in other forums is permitted, provided the original author(s) or licensor are credited and that the original publication in this journal is cited, in accordance with accepted academic practice. No use, distribution or reproduction is permitted which does not comply with these terms. 